Supporting Information for

\title{
Silver Nanoparticle-Decorated Shape-memory Polystyrene Sheets as Highly Sensitive Surface-enhanced Raman Scattering Substrates with a Thermally Inducible Hot Spot Effect
}

\author{
Zebasil Tassew Mengesha and Jyisy Yang ${ }^{*}$ \\ Department of Chemistry, National Chung Hsing University, Taichung 402, Taiwan
}

*Author to whom correspondence should be addressed.

Phone: $+886-422840411$ ext. 514

Fax: +886-422862547

E-mail: jyisy@dragon.nchu.edu.tw

\section{Contents}

Figure S1. SEM images of SERS substrates before and after thermal treatment. Substrates were prepared with $10 \mathrm{mM} \mathrm{AgNO}_{3}$ and $0.5 \mathrm{M}$ glucose for a reaction time of 5 min.

Figure S2: SEM images of SERS substrates before and after thermal treatment. Substrates were prepared with $20 \mathrm{mM} \mathrm{AgNO}_{3}$ and $0.5 \mathrm{M}$ glucose for a reaction time of $5 \mathrm{~min}$.

Figure S3: SEM images of SERS substrates before and after thermal treatment. Substrates were prepared with $50 \mathrm{mM} \mathrm{AgNO}_{3}$ and $0.5 \mathrm{M}$ glucose for a reaction time of $5 \mathrm{~min}$.

Figure S4: SEM images of SERS substrates before and after thermal treatment. Substrates were prepared with $100 \mathrm{mM} \mathrm{AgNO}_{3}$ and $0.5 \mathrm{M}$ glucose for a reaction time of $5 \mathrm{~min}$.

Figure 5: SERS intensity of pHTP on Ag@SMP substrate before thermal treatment (a). The corresponding increases of SERS intensities of pHTP on substrate after thermal treatment (b). The Ag@SMP substrates were prepared with $10 \mathrm{mM}(\diamond), 20 \mathrm{mM}(\boldsymbol{\square})$ and $50 \mathrm{mM}(\boldsymbol{\Delta}) \mathrm{AgNO}_{3}$.

Figure S6: SERS spectra of adenine deposited on AgNPs@SMP with different surface coverage areas. $\mathrm{Ag} @ \mathrm{SMP}$ substrates were prepared through reaction in $20 \mathrm{mM} \mathrm{AgNO}$ for $5 \mathrm{~min}$.

Figure S7: Relationship between Raman intensity of adenine at $735 \mathrm{~cm}^{-1}$ and surface coverage of adenine on shrunk Ag@SMP. The dashed line is the fitted result with an equation of exponential increase. The solid line is the fitted result with a linear equation on surface coverage lower than $7 \mathrm{ng} / \mathrm{cm}^{2}$. 

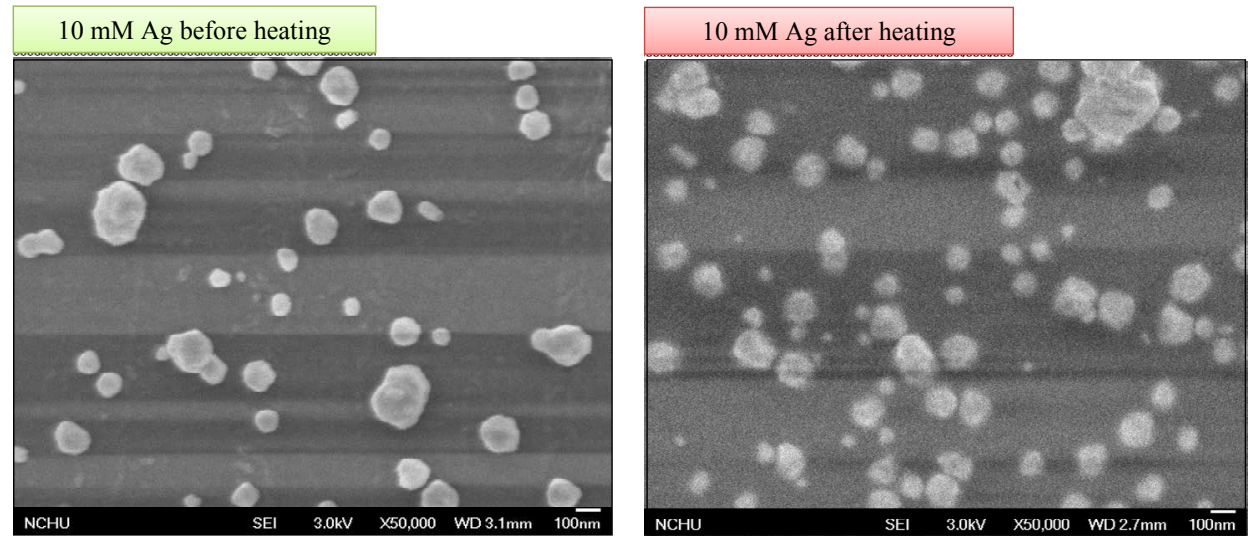

Figure S1. SEM images of SERS substrates before and after thermal treatment. Substrates were prepared with $10 \mathrm{mM} \mathrm{AgNO}_{3}$ and $0.5 \mathrm{M}$ glucose for a reaction time of $5 \mathrm{~min}$. 

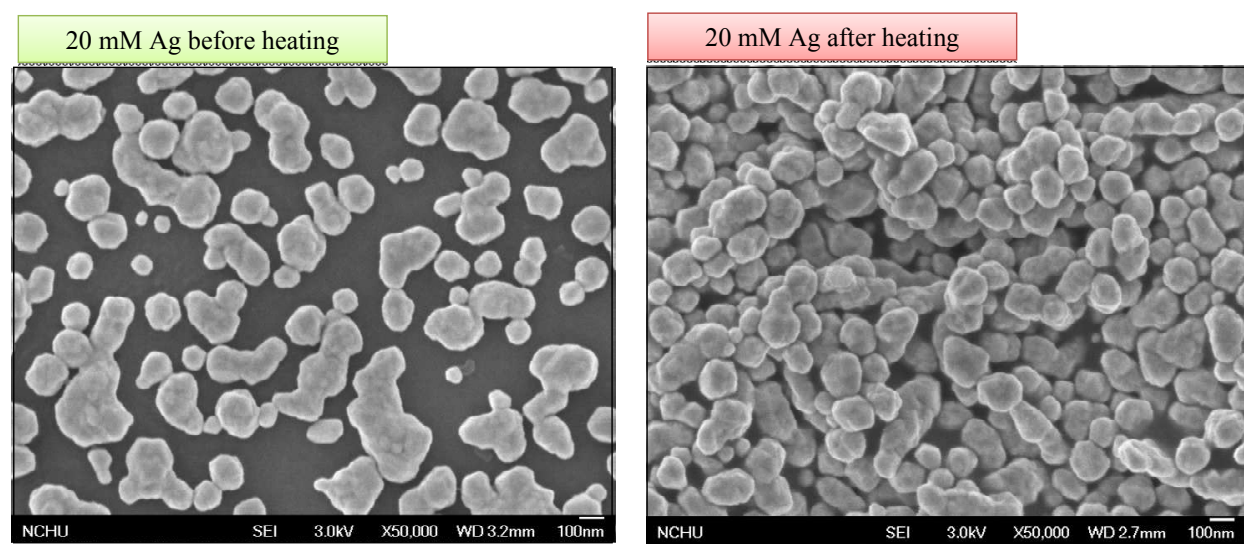

Figure S2: SEM images of SERS substrates before and after thermal treatment. Substrates were prepared with $20 \mathrm{mM} \mathrm{AgNO}_{3}$ and $0.5 \mathrm{M}$ glucose for a reaction time of 5 min. 

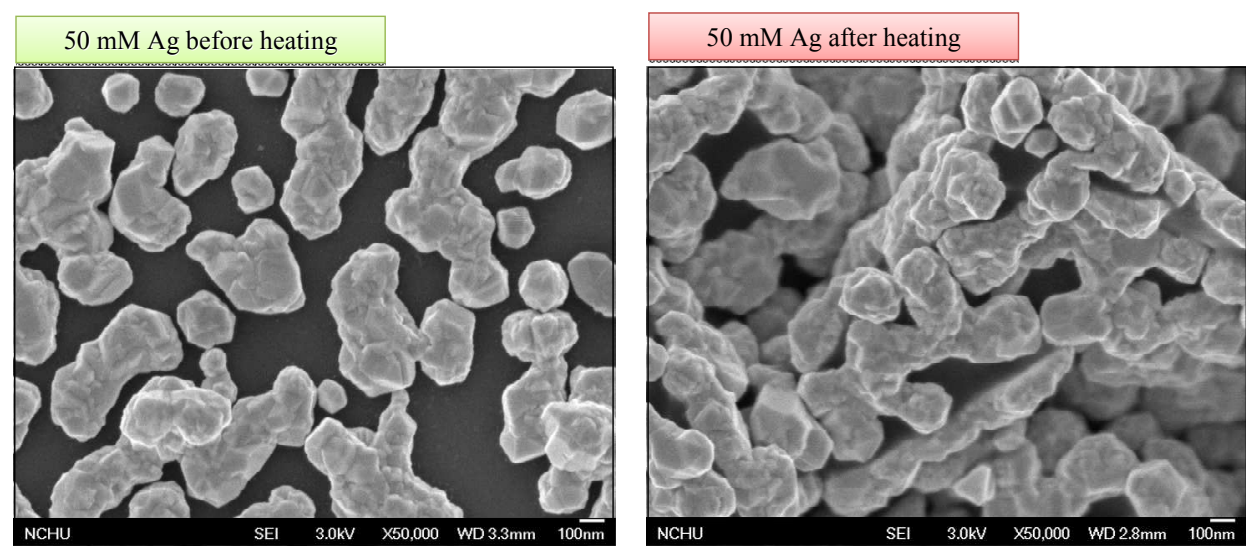

Figure S3: SEM images of SERS substrates before and after thermal treatment.

Substrates were prepared with $50 \mathrm{mM} \mathrm{AgNO}_{3}$ and $0.5 \mathrm{M}$ glucose for a reaction time of $5 \mathrm{~min}$. 

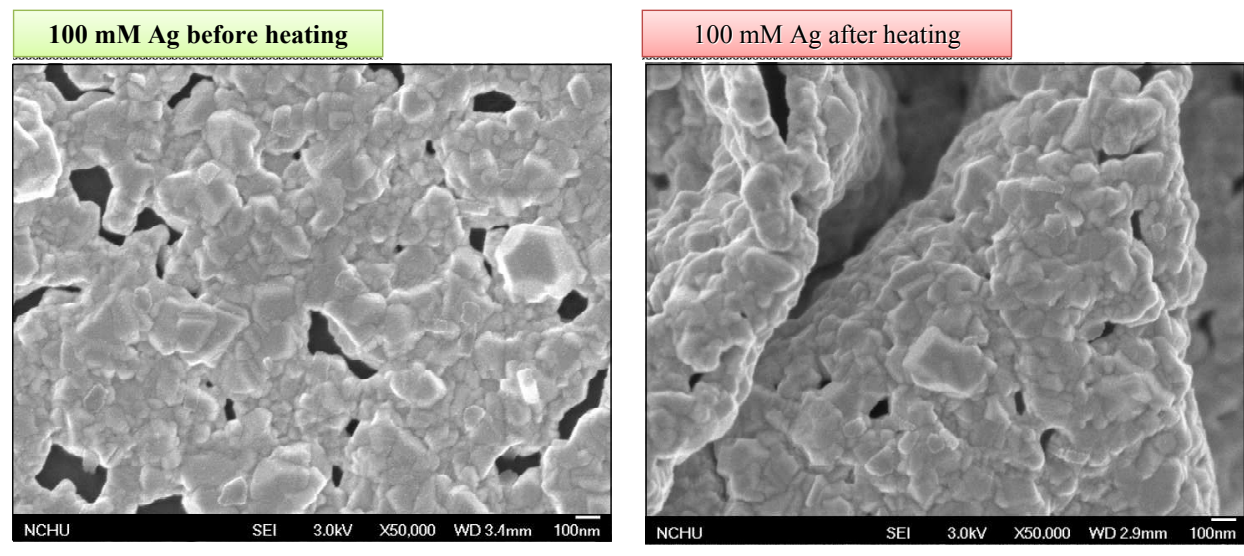

Figure S4: SEM images of SERS substrates before and after thermal treatment. Substrates were prepared with $100 \mathrm{mM} \mathrm{AgNO}_{3}$ and $0.5 \mathrm{M}$ glucose for a reaction time of $5 \mathrm{~min}$. 

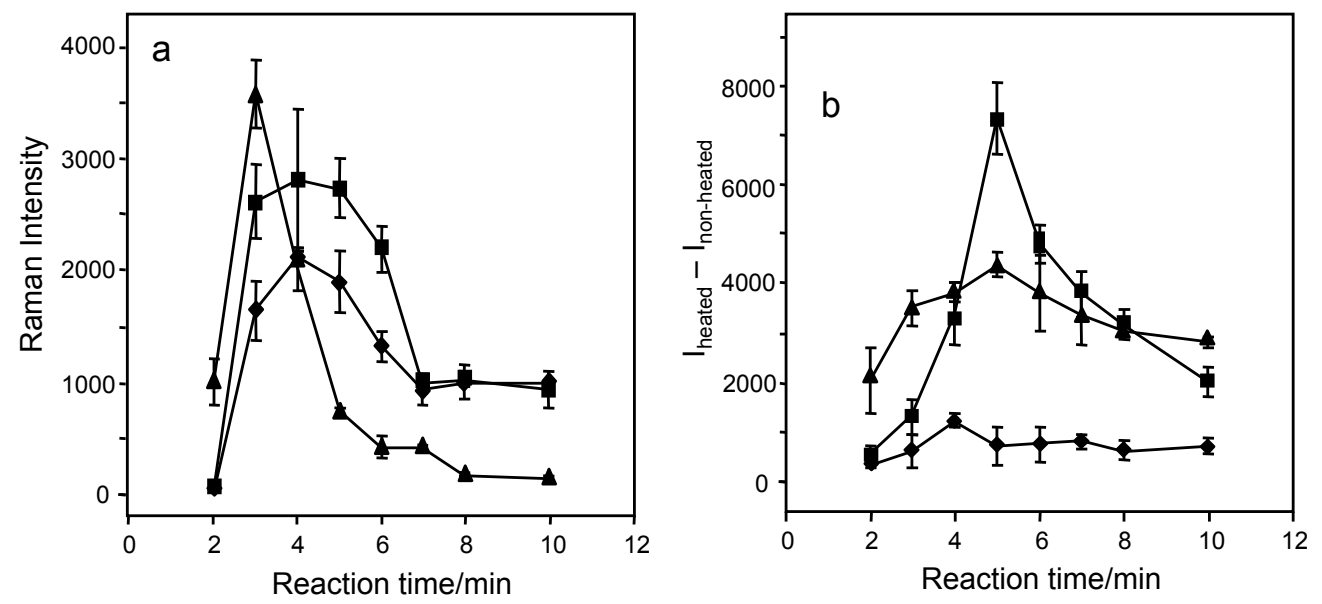

Figure 5: SERS intensity of pHTP on Ag@SMP substrate before thermal treatment (a). The corresponding increases of SERS intensities of pHTP on substrate after thermal treatment (b). The Ag@SMP substrates were prepared with $10 \mathrm{mM}(\diamond), 20 \mathrm{mM}(\mathbf{\square})$ and $50 \mathrm{mM}(\boldsymbol{\Delta}) \mathrm{AgNO}_{3}$. 


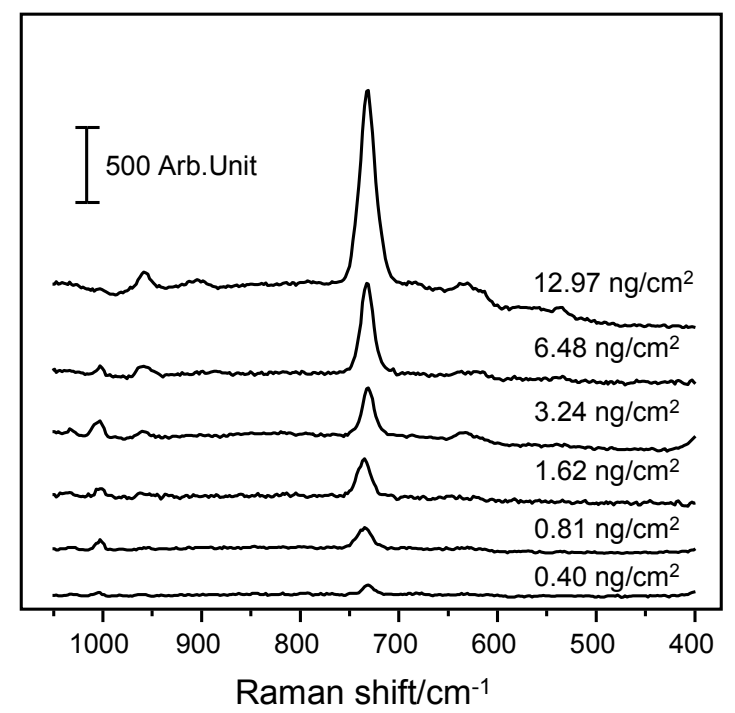

Figure S6: SERS spectra of adenine deposited on AgNPs@SMP with different surface coverage areas. Ag@SMP substrates were prepared through reaction in $20 \mathrm{mM} \mathrm{\textrm {AgNO } _ { 3 }}$ for $5 \mathrm{~min}$. 


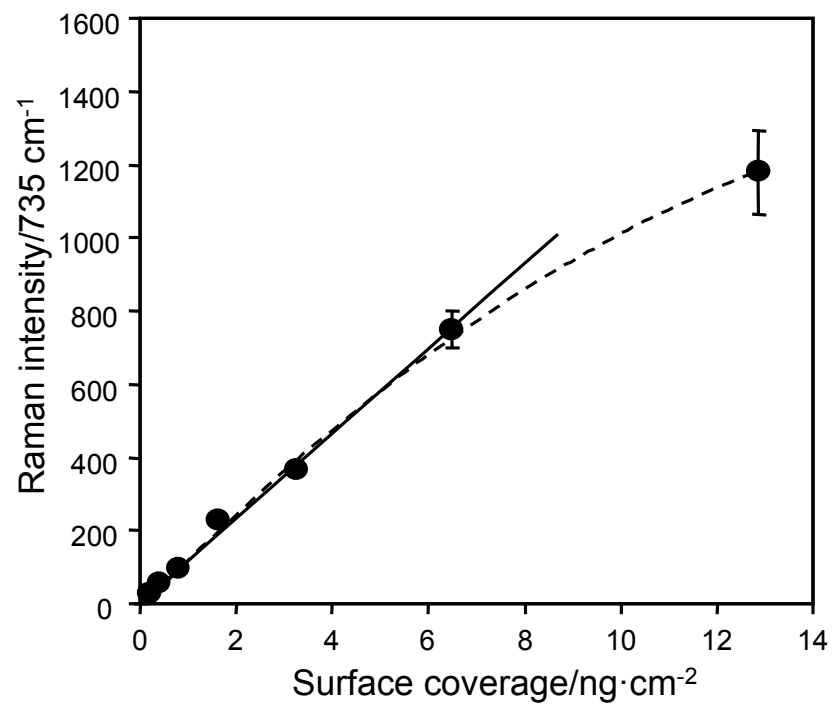

Figure S7: Relationship between Raman intensity of adenine at $735 \mathrm{~cm}^{-1}$ and surface coverage of adenine on shrunk Ag@SMP. The dashed line is the fitted result with an equation of exponential increase. The solid line is the fitted result with a linear equation on surface coverage lower than $7 \mathrm{ng} / \mathrm{cm}^{2}$. The error bar represents one SD from the mean, which was calculated from the spectra acquired at three different locations for each of the three substrates. 